REVISÃO DE LITERATURA

\section{COVID- 19: CONSIDERAÇÕES ATUAIS SOBRE A TRANSMISSÃO SALIVAR EM HUMANOS E RECOMENDAÇÕES PARA CIRURGIÕES DENTISTAS}

\section{COVID- 19: CURRENT CONSIDERATIONS ON HUMAN'S SALIVARY TRANSMISSION AND RECOMMENDATIONS FOR DENTAL SURGEONS}

Ana Cláudia Garcia Rosa ${ }^{1}$.

\section{RESUMO}

Este trabalho tem por objetivo realizar uma breve revisão de literatura para profissionais de odontologia, com informações atualizadas sobre a patogenicidade do vírus transmissor da COVID-19 (SARS-CoV-2), os possíveis mecanismos de infecção das células das glândulas salivares orais e o papel atual da saliva na transmissibilidade e sobrevivência do vírus. Foram sugeridos protocolos de controles de infecção no consultório odontológico visando minimizar a transmissibilidade entre profissionais de saúde e pacientes.

Palavras-chave: COVID-19; Betacoronavirus; Odontologia Comunitária

\section{ABSTRACT}

This work aims to perform a brief literature review for dental professionals, with updated information on the pathogenicity of the COVID-19 transmitting virus (SARS-CoV-2), the possible mechanisms of infection of the oral salivary glands and the current role of saliva in the transmissibility and survival of the virus. Protocols for infection control in the dental office have been suggested to minimize transmissibility between health professionals and patients.

Keywords: Coronavirus Infections; Betacoronavirus; Community Dentistry
Instituição: ${ }^{1} \mathrm{DDS}, \mathrm{PhD}$, docente curso Medicina Universidade Federal do Tocantins, Palmas, Brasil.

Autor correspondente: Ana Cláudia Garcia Rosa. Universidade Federal do Tocantins, Curso de Medicina. Quadra 109 Norte, Avenida NS-15, ALCNO-14. Plano Diretor Norte | 77001-090 | Palmas/TO. Fone: +55 (63) 3229- 4658. Email: anaclaudiagarcia@uft.edu.br

Editor: Carvalho A. A. B. Medicina, Universidade Federal do Tocantins, Brasil.

Publicado: 27 de julho de 2020.

Direitos Autorais: (C) 2020 Rosa et al. Este é um artigo de acesso aberto que permite o uso, a distribuição e a reprodução sem restrições em qualquer meio, desde que o autor original e a fonte sejam creditados.

Conflito de interesses: os autores declararam que não existem conflitos de interesses. 


\section{INTRODUÇÃO}

Um surto de pneumonia viral teve origem na cidade de Wuhan, China, no final de dezembro de 2019¹. A doença rapidamente se espalhou de Wuhan para a maioria dos países do mundo, e a Organização Mundial da Saúde (OMS) declarou, em 30 de janeiro de 2020, que o surto da doença constituía uma Emergência de Saúde Pública de Importância Internacional - o mais alto nível de alerta da Organização, conforme previsto no Regulamento Sanitário Internacional ${ }^{2}$.

O agente infeccioso dessa pneumonia viral foi identificado como um novo coronavírus, o sétimo membro de uma família de coronavírus que infectam humanos ${ }^{2,3}$. O Comitê Internacional de Taxonomia de Vírus nomeou esse novo agente infeccioso como "SARS-CoV-2", devido a semelhanças filogenéticas e taxonômicas com o SARS-CoV e o coronavírus da síndrome respiratória do Oriente Médio (MERS-CoV), que em 2002-2003 e em 2012, respectivamente, causaram doenças respiratórias graves fatais ${ }^{3,4,5}$.

Em 11 de fevereiro de 2020, a OMS nomeou a nova pneumonia viral como COVID-19 e em 11 de março de 2020, a doença foi caracterizada como uma pandemia².

Os sintomas clínicos típicos dos pacientes com COVID-19 são febre, tosse e mialgia ou fadiga, com TC torácica anormal, e os sintomas menos comuns são produção de escarro, cefaleia, hemoptise e diarréia ${ }^{6}$. Acredita-se que homens mais velhos estejam mais propensos a desenvolver doenças respiratórias graves em decorrência da COVID-19 ${ }^{7}$. Diversas vacinas e medicamentos têm sido testados com o intuito de se prevenir ou combater a infecção, entretanto, até a presente data, não se conhece um meio de prevenção ou tratamento específico.

\section{Características e patogenicidade do SARS-CoV-2}

Os coronavírus pertencem à família dos Coronaviridae, da ordem Nidovirais, que contêm como genoma um grande RNA único, de cadeia positiva ${ }^{8}$. Atualmente, existem quatro gêneros de coronavírus: $\alpha \mathrm{CoV}, \beta-\mathrm{CoV}, \gamma-\mathrm{CoV}$ e $\delta$-CoV ${ }^{9}$. O $\alpha$ $\mathrm{CoV}$ e o $\beta$-CoV infectam principalmente o sistema nervoso, respiratório, gastrointestinal e central de humanos e mamíferos, enquanto o $\gamma-\mathrm{CoV}$ e $\delta$-CoV infectam principalmente as aves ${ }^{9}$. O SARS-CoV e o MERS-CoV, que causam doenças respiratórias graves, pertencem ao $\beta$ CoV23,24. O SARS-CoV-2 (causador da COVID-19) também pertence ao $\beta-\mathrm{CoV}$, de acordo com a análise filogenética baseada no genoma viral ${ }^{10}$. Embora a similaridade da sequência nucleotídica entre SARS-CoV-2 e SARS-CoV ou MERS-CoV seja menor que $80 \%$, o SARS-CoV-2 também pode causar a infecção fetal e se espalha mais rapidamente do que os outros dois coronavírus ${ }^{4,5,8,10}$.

Para infectar a célula hospedeira, a proteína S do SARS-CoV-2 se liga a receptores das células-alvo ${ }^{11,12}$. Embora haja quatro variações de aminoácidos entre a proteína S do SARS-CoV-2 e a proteína $\mathrm{S}$ do SARS-CoV, o novo coronavírus também pode se ligar à enzima conversora de angiotensina 2 humana
(ACE2), o mesmo receptor hospedeiro para o SARS-CoV ${ }^{12}$. Os primeiros estudos sobre esse assunto foram publicados por Zhou et al., que conduziram estudos de infectividade pelo vírus e confirmaram que o receptor ACE2 é necessário para a entrada de SARS-CoV-2 em células de morcegos e células $H e L a^{13}$. Em seguida, Hoffmann et al. demostram que a entrada de SARS-CoV-2 na célula hospedeira depende de um processo chamado priming da proteína $S$, que é realizado por proteases celulares, como a serina protease TMPRSS2 ${ }^{14}$, um passo crucial leva à fusão das membranas virais e celulares. Este estudo também verificou que a atividade de TMPRSS2 é essencial para a disseminação viral e que a inibição de TMPRSS2 pode bloquear a infecção de células pulmonares ${ }^{14}$.

As células ACE2 positivas (ACE2+) estão abundantemente presentes em todo o trato respiratório ${ }^{15}$ e no trato gastrointestinal ${ }^{16}$. A alta afinidade entre a ACE2 humana e a proteína $S$ do vírus sugere que populações humanas com maior expressão de ACE2 celular podem ser mais suscetíveis à infecção pelo SARS-CoV- ${ }^{17}$. Mutações no gene ACE2 também poderiam influenciar a capacidade do vírus de reconhecer e infectar uma célula humana ${ }^{18}$.

Uma maior compreensão das interações entre o SARS-CoV-2 e - receptor celular humano ACE2 poderia auxiliar no desenvolvimento de opções de tratamento e estratégias de combate à infecção, como o desenvolvimento de vacinas ou anticorpos neutralizantes.

\section{Identificação do SARS-CoV-2 nas células das glândulas salivares e na saliva}

Os meios de transmissão comuns de COVID-19 incluem transmissão direta (por meio de tosse, espirro e inalação de gotículas) e transmissão de contato (contato com as mucosas bucais, nasais e oculares) ${ }^{19}$. Estudos recentes sugerem a ocorrência de transmissão oro-fecal do vírus ${ }^{16}$ e um relato de um caso de infecção por SARS-CoV-2 na Alemanha indica que a transmissão também pode ocorrer através do contato com pacientes assintomáticos ${ }^{20}$.

O SARS-CoV-2 também parece ser transmitido direta ou indiretamente pela saliva e pode ser que as secreções salivares sejam um amplo reservatório viral em humanos. Alguns fatores suportam essas hipóteses: (1) as células epiteliais ductais de glândulas salivares menores são alvos da infecção pelo SARS-CoV ${ }^{22}$ e acredita-se que estas células também sejam alvos da infecção pelo SARS-CoV-2, uma vez que expressam o receptor ACE2, necessário para a entrada do novo coronavírus no interior celular; (2) um estudo recente analisou a expressão do gene ACE2 em órgãos humanos no portal GTEx (https://www.gtexportal.org/home/gene/ ACE2 \# geneExpression) e verificou que a expressão do receptor ACE2 em glândulas salivares menores foi bem maior que nos pulmões, sugerindo a possibilidade de infecção por COVID-19 via transmissão salivar ${ }^{23}$; (3) partículas virais puderam ser cultivadas em amostras de saliva de indivíduos infectados e acredita-se que o SARS-CoV-2 pode ser transmitido por infecção assintomática, com origem na saliva infectada ${ }^{24}$; (5) a presença do ácido nucleico do SARS-CoV-2 na saliva originária 
das glândulas salivares menores da cavidade oral parece ser um indicador de mau prognóstico para a COVID-1925.

Maiores investigações sobre o comportamento do SARS-CoV-2 nas secreções e células ductais e acinares das glândulas salivares poderia fornecer subsídios para o desenvolvimento de novos meios de diagnóstico, prevenção e tratamento, como por exemplo, testes de ação rápida para triagem de COVID-19 por meio da saliva.

\section{Controles de infecção para consultórios odontológicos}

Tendo em vista a possibilidade de a saliva ser um grande reservatório viral e um importante meio de transmissão do COVID-19, os profissionais da área odontológica devem redobrar os cuidados nos atendimentos a pacientes durante o período de pandemia por COVID-19 e devem estar familiarizados com os principais sinais e sintomas da doença. É importante saber identificar pacientes suspeitos e adotar medidas protetoras durante a prática clínica, a fim de impedir a transmissão no ambiente de trabalho. Algumas medidas de controle de infecção devem ser reforçadas, tendo em vista a possibilidade de transmissão em pacientes assintomáticos. Os protocolos de controles de infecção aqui apresentados foram traduzidos, atualizados e adaptados de Peng et al. ${ }^{15}$.

\section{Avaliação do paciente}

Antes de tudo, os profissionais de odontologia devem ser capazes de identificar um caso suspeito de COVID-19. Para isso, duas medidas básicas devem ser adotadas: (1) a temperatura corporal do paciente deve ser aferida, preferencialmente com um termômetro digital infravermelho (sem contato), na testa ${ }^{15}$; (2) um questionário para rastreamento de pacientes infectados deve ser aplicado antes do atendimento odontológico, com as seguintes perguntas (que podem variar conforme as recomendações dos órgãos de vigilância em saúde locais ou Ministério da Saúde): (a) você tem ou teve febre nos últimos 14 dias? ${ }^{15}$ (b) você teve problemas respiratórios, como tosse ou dificuldade em respirar, nos últimos 14 dias? ${ }^{15}$ (c) nos últimos 14 dias, você viajou para outras cidades ou países ou visitou locais com transmissão documentada de COVID-19? ${ }^{15}$ (d) você entrou em contato com um paciente com infecção confirmada por COVID-19 nos últimos 14 dias? ${ }^{15}$ (e) você entrou em contato com pessoas que tiveram febre ou problemas respiratórios nos últimos 14 dias? ${ }^{15}$ (f) há pelo menos duas pessoas que tiveram febre ou problemas respiratórios nos últimos 14 dias tendo contato próximo com você? ${ }^{15}$ (g) você participou, recentemente, de alguma reunião, encontro ou teve contato próximo com muitas pessoas desconhecidas? ${ }^{15}$

Se um paciente responder "não" a todas as perguntas de triagem e sua temperatura corporal estiver abaixo de $37,3^{\circ} \mathrm{C}$, o cirurgião dentista poderá tratá-lo com medidas de proteção extra e evitar o máximo possível de procedimentos que gerem aerossóis $^{15}$.
Se um paciente responder "não" a todas as perguntas de triagem, mas sua temperatura corporal não for inferior a 37,3 ${ }^{\circ} \mathrm{C}$, o paciente deve ser encaminhado para avaliação médica ${ }^{15}$.

Se um paciente responder "sim" a qualquer uma das perguntas de triagem e sua temperatura corporal estiver abaixo de $37,3^{\circ}$ C, o cirurgião dentista poderá adiar o tratamento por até 14 dias após o evento de exposição (período em que o paciente poderá manifestar os sintomas). 0 paciente deve ser instruído a se manter em isolamento domiciliar e relatar qualquer experiência como febre ou síndrome gripal ao serviço de atenção primária à saúde local ${ }^{15}$.

Se um paciente responder "sim" a qualquer uma das perguntas de triagem, e sua temperatura corporal não for inferior a $37,3^{\circ} \mathrm{C}$, o paciente deve ser imediatamente colocado em isolamento domiciliar e os profissionais de odontologia devem notificar o serviço de controle de infecção local / regional ${ }^{15}$.

\section{Higiene das mãos}

O reforço para uma boa higiene das mãos é de suma importância. Os profissionais devem lavar as mãos antes e após cada atendimento odontológico ${ }^{15}$.

\section{Medidas de proteção individual}

Atualmente, não há diretrizes específicas para a proteção de profissionais de odontologia contra a infecção por SARS-CoV-2 nas clínicas odontológicas ${ }^{15}$. É altamente recomendável para todos os serviços de saúde odontológicos o uso de equipamentos de proteção de barreira, incluindo óculos de proteção, máscaras, luvas, gorros, protetores faciais e jalecos/ capotes de proteção durante o período pandêmico de COVID$19^{15}$. Com base na possibilidade de disseminação da infecção, são recomendadas medidas de proteção em três níveis aos profissionais de odontologia, para situações específicas: (1) Proteção primária (proteção padrão para funcionários em ambientes clínicos). Uso de touca descartável, máscara cirúrgica descartável, jaleco, óculos de proteção ou protetor facial e luvas de látex ou nitrila ${ }^{15}$; (2) Proteção secundária (proteção para profissionais de odontologia). Uso de touca descartável, protetor facial, respirador descartável N95 ou PFF 2, óculos de proteção, protetor facial e jaleco, com roupas descartáveis de isolamento ou cirúrgicas externas e luvas descartáveis de látex ${ }^{15}$; (3) Proteção terciária (proteção reforçada ao entrar em contato com o paciente com suspeita ou confirmação de COVID-19). É necessário um traje de proteção especial. Se não houver roupas de proteção específicas, usar jaleco com roupas de proteção descartáveis extras, além de touca descartável, óculos de proteção, protetor facial, respirador descartável N95 ou PFF 2, luvas de látex descartáveis e protetores descartáveis para os pés ${ }^{15}$.

\section{Enxaguatórios bucais}

A clorexidina, parece não ser eficaz para inativar o SARS-CoV$2^{15}$. Como o SARS-CoV-2 é vulnerável à oxidação, recomendase o enxágue bucal pré-procedimento com agentes oxidantes 
como peróxido de hidrogênio a $1 \%$ ou iodopovidona a $0,2 \%$, com o objetivo de reduzir a carga viral na cavidade oral.

\section{Isolamento com diques de borracha}

O uso de diques de borracha pode minimizar significativamente a produção de aerossóis ou respingos contaminados com saliva e sangue, principalmente nos casos em que são utilizadas peças de mão de alta rotação e dispositivos ultrassônicos ${ }^{15}$. Deve-se usar sucção com bomba a vácuo durante todo e qualquer procedimento odontológico, mesmo com o dique ${ }^{15}$. Nos casos em que o isolamento absoluto não for possível, recomenda-se substituir o uso de peças de mão de alta rotação ou aparelhos de ultrassom por outros meios de tratamento, como o uso de Carisolv ${ }^{\circledR}$ ou curetas para raspagem periodontal, a fim de minimizar ao máximo a geração de aerossóis ${ }^{15}$.

\section{Peças de mão (canetas de alta e baixa rotação)}

Peças de mão com válvulas antirrefluxo são fortemente recomendadas como medida preventiva extra para o controle das infecções cruzadas ${ }^{15}$. Portanto, o uso de peças de mão odontológicas sem sistema antirrefluxo deve ser proibido durante o período epidêmico do COVID-19 ${ }^{15}$.

\section{Gestão de resíduos dos serviços de saúde}

Os resíduos de serviços de saúde (incluindo equipamentos de proteção descartáveis após o uso) devem ser transportados para a área de armazenamento temporário do local de atendimento odontológico em tempo hábil. $\mathrm{O}$ instrumento $\mathrm{e}$ os itens reutilizáveis devem ser pré-tratados, limpos, esterilizados e armazenados adequadamente, de acordo com os protocolos estabelecidos pela ANVISA na RDC $n \cong 222$, de 28 de março de 2018. Resíduos domésticos gerados pelo tratamento de pacientes com suspeita ou confirmação de infecção por COVID-19 devem ser considerados resíduos infecciosos ${ }^{15}$. Para acondicionamento dos resíduos, devem ser utilizados sacos de lixo resistentes de cor branco leitosa e com ligadura para fechamento. Os sacos de embalagem devem ser identificados e descartados de acordo com os requisitos de boas práticas de gerenciamento dos resíduos de serviços de saúde (RDC n $\cong 222$, de 28 de março de 2018) ${ }^{26}$.

\section{COMENTÁRIOS}

Os protocolos de controle de infecção no consultório odontológico foram traduzidos, atualizados e adaptados de: Peng $X, X u X$, Li Y, Cheng L, Zhou X, Ren B. Transmission routes of 2019-nCoV and controls in dental practice. Int J Oral Sci. 2020 Mar 3;12(1):9. doi: 10.1038/s41368-020-0075-9.

O artigo original está sob licença Creative Commons Attribution $\quad 4.0 \quad$ International License (https://creativecommons.org/licenses/by/4.0)

\section{REFERÊNCIAS BIBLIOGRÁFICAS}

1. ADASHI, T. et al. 1. Zhu N, Zhang D, Wang W, et al. A Novel Coronavirus from Patients with Pneumonia in China, 2019.
$N$ Engl J Med.
2020;382(8):727-733 doi:10.1056/NEJMoa2001017

2. OPAS Brasil [homepage on the Internet]. Folha informativa - COVID-19 (doença causada pelo novo coronavírus) [cited 2020 Apr30]. Available from: https://www.paho.org/bra/index.php?option=com content

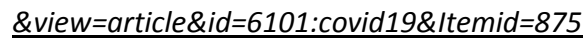

3. Zhou P, Yang XL, Wang XG, et al. A pneumonia outbreak associated with a new coronavirus of probable bat origin. Nature. 2020;579(7798):270-273. doi:10.1038/s41586-0202012-7

4. Falsey $A R$, Walsh EE. Novel coronavirus and severe acute respiratory syndrome. Lancet. 2003;361(9366):1312-1313. doi:10.1016/S0140-6736(03)13084-X

5. The Lancet. MERS-COV: a global challenge. Lancet 2013;381(9882):1960. doi:10.1016/S0140-6736(13)61184-8

6. Huang $C$, Wang $Y$, Li $X$, et al. Clinical features of patients infected with 2019 novel coronavirus in Wuhan, China [published correction appears in Lancet. 2020 Jan 30]. Lancet. 2020;395(10223):497-506. doi:10.1016/S01406736(20)30183-5

7. Chen N, Zhou M, Dong X, et al. Epidemiological and clinical characteristics of 99 cases of 2019 novel coronavirus pneumonia in Wuhan, China: a descriptive study. Lancet. 2020;395(10223):507-513. doi:10.1016/S0140$6736(20) 30211-7$

8. Fehr AR, Perlman S. Coronaviruses: an overview of their replication and pathogenesis. Methods Mol Biol. 2015;1282:1-23. doi:10.1007/978-1-4939-2438-7_1

9. Fan, Y., Zhao, K., Shi, Z. L., \& Zhou, P. Bat Coronaviruses in China. Viruses. 2019 11(3), 210. https://doi.org/10.3390/v11030210

10. Wu F, Zhao $S, Y u B$, et al. A new coronavirus associated with human respiratory disease in China [published correction appears in Nature. 2020 Apr;580(7803):E7]. Nature. 2020;579(7798):265-269. doi:10.1038/s41586-020-2008-3

11. Belouzard S, Millet JK, Licitra BN, Whittaker GR. Mechanisms of coronavirus cell entry mediated by the viral spike protein. Viruses. 2012;4(6):1011-1033. doi:10.3390/v4061011

12. Wan Y, Shang J, Graham R, Baric RS, Li F. Receptor Recognition by the Novel Coronavirus from Wuhan: an Analysis Based on Decade-Long Structural Studies of SARS Coronavirus. J Virol. 2020;94(7):e00127-20. Published 2020 Mar 17. doi:10.1128/JVI.00127-20

13. Zhou $P$, Yang XL, Wang XG, et al. A pneumonia outbreak associated with a new coronavirus of probable bat origin. Nature. 2020;579(7798):270-273. doi:10.1038/s41586-0202012-7

14. Hoffmann M, Kleine-Weber H, Schroeder S, et al. SARS-CoV2 Cell Entry Depends on ACE2 and TMPRSS2 and Is Blocked by a Clinically Proven Protease Inhibitor. Cell. 2020;181(2):271-280.e8. doi:10.1016/j.cell.2020.02.052 
15. Peng $X, X u X, L i Y$, Cheng L, Zhou $X$, Ren B. Transmission routes of 2019-nCoV and controls in dental practice. Int $J$ Oral Sci. 2020;12(1):9. Published 2020 Mar 3. doi:10.1038/s41368-020-0075-9

16. Hindson J. COVID-19: faecal-oral transmission? [published online ahead of print, 2020 Mar 25]. Nat Rev Gastroenterol Hepatol. 2020;10.1038/s41575-020-0295-7. doi:10.1038/s41575-020-0295-7

17. Wu $C$, Zheng $S$, Chen $Y$, Zheng $M$. Single-cell RNA expression profiling of ACE2, the putative receptor of Wuhan 2019nCoV, in the nasal tissue. medRxiv; 2020. doi: 10.1101/2020.02.11.20022228.

18. MSN News [homepage on the Internet]. Coronavirus: Genes may explain why some face greater danger than others [cited 2020 Apr30]. Available from: https://www.msn.com/en-us/news/other/coronavirusgenes-may-explain-why-some-face-greater-danger-thanothers/ar-BB12sfPr

19. Lu CW, Liu XF, Jia ZF. 2019-nCoV transmission through the ocular surface must not be ignored. Lancet. 2020;395(10224):e39. doi:10.1016/S0140-6736(20)30313-5

20. Rothe $C$, Schunk $M$, Sothmann $P$, et al. Transmission of 2019-nCoV Infection from an Asymptomatic Contact in Germany. N Engl J Med. 2020;382(10):970-971. doi:10.1056/NEJMc2001468

21. Kessler AT, Bhatt AA. Review of the Major and Minor Salivary Glands, Part 1: Anatomy, Infectious, and Inflammatory Processes. J Clin Imaging Sci. 2018;8:47. Published 2018 Nov 15. doi:10.4103/jcis.JCIS_45_18

22. Liu L, Wei $Q$, Alvarez $X$, et al. Epithelial cells lining salivary gland ducts are early target cells of severe acute respiratory syndrome coronavirus infection in the upper respiratory tracts of rhesus macaques. J Virol. 2011;85(8):4025-4030. doi:10.1128/JVI.02292-10

23. Xu $R$, Cui B, Duan X, Zhang $P$, Zhou X, Yuan Q. Saliva: potential diagnostic value and transmission of 2019-nCoV. Int J Oral Sci. 2020;12(1):11. Published 2020 Apr 17. doi:10.1038/s41368-020-0080-z

24. To KK, Tsang OT, Chik-Yan Yip C, et al. Consistent detection of 2019 novel coronavirus in saliva [published online ahead of print, $2020 \mathrm{Feb}$ 12]. Clin Infect Dis. 2020;ciaa149. doi:10.1093/cid/ciaa149

25. Xu, R., Cui, B., Duan, X. et al. Saliva: potential diagnostic value and transmission of 2019-nCoV. Int J Oral Sci 12, 11 (2020). https://doi.org/10.1038/s41368-020-0080-z

26. ANVISA [homepage on the Internet] RDC $n \cong 222$, de 28 de março de 2018 [cited 2020 Apr30]. Available from: http://portal.anvisa.gov.br/documents/10181/3427425/RD c 2222018 .pdf/c5d3081d-b331-4626-8448c9aa426ec410 